\title{
The Effects of Tourism Architecture on Island Ecosystems
}

\author{
Lourdes Ruiz \\ International University of Ecuador, Quito, Ecuador \\ Email: Iruiz@internacional.edu.ec
}

Received 16 October 2015; accepted 29 November 2015; published 2 December 2015

Copyright (C) 2015 by author and Scientific Research Publishing Inc.

This work is licensed under the Creative Commons Attribution International License (CC BY). http://creativecommons.org/licenses/by/4.0/

c) (i) Open Access

\begin{abstract}
This research aims to propose environmental prevention and mitigation on fragile coastal ecosystems due to the actions of the tourist architecture, using methods of life-cycle assessment of buildings, matrix methods of the actions that cause severe environmental impact and statistical processing through multivariate analysis. A study of projects was undertaken in Cayo Coco located to the north of Ciego de Avila, Cuba, being built today and where the tourist development of the archipelago Sabana-Camaguey started. It has been determined that suitable architecture would decrease the negative impact of these fragile ecosystems.
\end{abstract}

\section{Keywords}

\section{Architecture, Tourism, Island Ecosystems}

\section{Introduction}

Tourism is recognized as an important source of foreign currencies, being an important industry in Cuba. Given the current status of economy and the relatively good health of natural environment in the archipelago Sabana Camaguey, tourism based on the environment is the most compatible option of development. This kind of tourism not only is sensitive to the marine and coastal habitats and species, but also encourages the quality of them. Thus, the reasons that tourists choose the islands are: firstly, climate and, secondly, the existence of a physical separation from the continents, making the islands a special and attractive place for travelers, and the attraction posed by natural and cultural resources that exist in these geographic areas should also be added as a reason.

Tourism to the islands is the second most important holiday destination, just behind historic cities. Ecotourism in Dominica and the Seychelles, diving in Malta and the Maldives, music tourism of Cape Verde, cultural tourism in the Marshall Islands, the tourism festival in the Bahamas, tourism meetings and conventions in Trinidad and Tobago, and medical tourism in Barbados, are just some of the strategies that small island states resort to 


\section{[1].}

Small island state governments have sought to rebut such accusations. Indeed, this is the very same argument making the case for the structural vulnerability of small island states. With very few exceptions, all industrialization strategies in small island states have failed. And even amongst the few exceptions-Barbados, Fiji, Malta, Mauritius - any success has been short-lived. Generic environmental, economic, and social problems ensue from a dependence on producing a narrow range of cash crops-the typical suspects being banana, cocoa, coffee, copra, ginger, guano, sugar, tobacco and vanilla — for sale in the world economy, plus out-migration and remittances, and foreign aid [1].

The rise of new innovative construction technologies and the high complexity of current tourism projects impose special attention on the problem of prediction and estimation of potential failures, which can through their adverse impact determine unimagined scenarios exceeding the limits for acceptable change of the vulnerable coastal ecosystems, because they jeopardize the development of sustainable tourism for society and the environment.

Moreover, the small islands are considered to be among the most vulnerable ecosystems in the world, due to the reduced size of their territory and their physical conditions of insularity, which increase the susceptibility and exposure of their natural or social systems to the impact of threats of a natural character or from mankind. They are fragile ecosystems, with highly physical and socio-cultural complexity in those inhabited islands. The mere description of island takes for granted that it is fragile, small, peripheral, and vulnerable [2].

In order to prevent ecological damage on small islands, one of the environmental management tools most commonly used is the integrated management of the coastal area which attempts to coordinate planning and action, involving local communities and institutions so as to design new strategies in the hope of achieving equitable and sustainable solutions. The main topics covered are the management of fresh water; the maintenance of coastal communities and the biodiversity that underpins them; migration and the quality of life of coastal human settlements; the impact of climate change; coastal erosion and rising sea level [3].

Besides the natural factors that have led to the deterioration of the beaches, man has increased erosion within adequate management of coastal vegetation and incorrect location of tourist facilities in areas of sunshine. In general these islands have high biodiversity and unique landscapes, a high dependence on imported products and an ever increasing pressure exerted on them by the development of tourism. They have a high vulnerability because they are subject to risks and natural disasters such as rising sea levels, increasing temperatures and the frequency of hurricanes and tsunamis. In addition they have few reserves of fresh water and sandy beaches with high ecological fragility eroded by different natural and anthropogenic causes [3].

Tourist architecture development on fragile coastal ecosystems plan was presenting a development stereotype that would be in conflict with important biological resources, and not in agreement with the evolution of the tourism market in the Caribbean and archipelago Sabana Camaguey.

Cuba is maintaining a sustained trend towards refining the decision making process regarding land use and physical planning as well an environmental issue in development at policy level. The Institute of Physical Planning (IPF) is the governing agency for physical planning and regulation of land use. IPF and its Provincial Directorates will collaborate with other relevant institutions of the project to establish a clear delineation between areas to be protected and areas prioritized for development. The Institute will also continue conceptual strategic environmental planning for other important keys where biodiversity could be seriously damaged by tourism construction development on fragile coastal ecosystems.

To incorporate the environmental dimension into the country's development, considerable supportive or enabling legislation has been formulated and approved. In the year 1994, as a result of increasing awareness of the crucial importance of the environmental dimensions of economic development and environmental and social sustainability, Cuba created the Ministry of Sciences, Technology and Environment (CITMA), with its Environment Agency, the Environments Units in CITMAs Provincial Delegations, the National Centre of Protected Areas, the Environmental Information and the Education Centre. Just before, the National Centre for Control and Management (CICA) was created. CICA together with the Provincial Delegations of CITMA will be charged with the gradual implementation of the vast Environmental Impact Assessment Tourism Programs in Cuba.

Institutional sustainability of tourism activities is guaranteed by the Government's recognition of the vital importance of protecting biodiversity and fragile ecosystems, as part of the country's natural capital on which its sustainable development depends. The Government will guarantee the functioning of the Protected Area System 
and the Council for Integrated Coastal Management upon completion of the tourism project, including the longterm monitoring programmer. Sustainability will be enhanced with a comprehensive legal framework; the Resolution on Environmental Impact Assessment (EIA), as well as the Decree-Law on Coastal Zones and other laws will contribute to the EIA process.

\section{Research Methodology}

The research methodology was based on information from quantitative research methods and qualitative analysis like:

- Method of consulting selected experts

- Compared scenarios method

- Non-parametric statistics

- Lifecycle analysis

- Environmental impact assessment

The method of consulting selected experts was used in the issue of the management of fragile ecosystems [3] Within this method, the selection of experts was conducted with the use of the process of quantifying the coefficient for competence $\mathrm{K}$ which was calculated in accordance with the opinion of each candidate on their level of knowledge about the problem to be solved and with the sources that will allow the criteria to be argued [4].

Case studies are analyzed on the projects of Cayo Coco a small island, recognized as part of the northern keys located in the Sabana Camagüey Archipelago, in the province of Ciego Avila in Cuba are analyzed. The physical and socio-economic environment of the site chosen for the case study was examined and was complemented with the scenario method compared to similar coastal ecosystems [5]. The results are given (Table 1).

The compared scenarios method which is one of the most optimal qualitative observation methods to compare projects in different biogeographic regions, in addition to diagnosis and monitoring of environmental changes, for a fixed period of time can incorporate other complementary analysis such as the aforementioned matrix methods [6].

Information from non-parametric statistics was processed. The analysis of the main components was used, a method which is feasible to use due to the characteristics of the selected variables: discrete, qualitative and measures on an ordinal scale [6]. Although there are several types of correlation coefficients, it was decided to use the Spearman rank order coefficient for allowing a greater number of variables correlated with matrices identifying environmental impacts. The results were classified according to the mathematical magnitude of the coefficients closest to 1 . Only the values of a first range or level of importance were considered and coefficients with values between 0.700 and 1 were brought together [6].

The lifecycle analysis which is one of the most accurate methods of environmental assessment focused on the sustainability of products, processes and services and saving materials and energy from various aspects identified in diagnostics or inventories and assessment of the potential impact of actions or activities that cause such impact. It is raised by several authors [7] [8] that there are many methodologies proposed in articles that aim to overcome the existing prejudices of architects and engineers on the complexity of the LCA. This LCA methodology can analyze the overall environmental impact during the life of a building [9].

Table 1. Result of the influence of each of the sources in their criteria.

\begin{tabular}{|c|c|c|c|}
\hline \multirow{2}{*}{ Sources of argument on the issue: architecture, tourism, island ecosystems } & \multicolumn{3}{|c|}{ Influence of each of the sources in their criteria } \\
\hline & High $(\mathrm{H})$ & Medium (M) & Low (L) \\
\hline 1. Research related to tourism architecture, sustainability, and island ecosystems & 0.5 & 0.38 & 0.1 \\
\hline $\begin{array}{l}\text { 2. Experience gained in working on the issue (undergraduate and graduate } \\
\text { received and/or given, scientific degrees, participation in scientific projects) }\end{array}$ & 0.5 & 0.35 & 0.13 \\
\hline 3. Participation in international and national workshops on the subject & 0.4 & 0.2 & 0.09 \\
\hline $\begin{array}{l}\text { 4. Analysis and knowledge of foreign specialized } \\
\text { literature and publications by national and foreign authors }\end{array}$ & 0.43 & 0.21 & 0.06 \\
\hline 5. Scientific and/or teaching expert category & 0.41 & 0.26 & 0.05 \\
\hline
\end{tabular}


The coefficients with values lower than these ranges mentioned were not considered on account of the little relevance produced by the figures, although they are present to a lesser extent, within the construction actions that cause environmental impact. The life-cycle assessment (LCA being the acronym in English) was performed, by way of identification matrices of impacting actions contained in the architectural projects. Finally the information was processed using non-parametric statistical analysis of main components and the results and conclusions of the research were obtained.

However, the assessment of the environmental impact of the construction technologies is a complex process given that there are many elements involved, combined in different operations and stages throughout its life. Although the analysis of the life cycles can be broken down into many more for the purposes of evaluating the effects of architectural projects in this work it is sufficient to use the following four cycles [7]:

- Cycle 1 Projects: includes all the indicators and activities involved in planning where conceptual designs with the loads of tourists and employees are planned, the urbanizations and the infrastructure, the geological investigations and others, as well as all activities of the architectural project up to the final stage. This cycle is the most important in the evaluation of a project [7]. In the cycle of projects environmental factors suffer changes related to the protected area proposed as a national park; the beach and the chains of fossil dunes; as well as the vegetation complexes of a sandy coast, xeromorphic scrub, ever green microphyll forest, the habitats of endemic wild life such as birds, fish, mollusks, amongst others [9].

- Cycle 2 Construction: includes all activities carried out in a work from the preparation of temporary facilities for workers, earth works, foundations, structures and finishes, exterior areas and ground and gardening, to the point of delivery to the tour operator [7]. During the second stage of construction, primary and secondary effects occur in the climate and environmental well-being; in geomorphology and geology of the cumulative plain and marine; in the complexes of sandy shoreline vegetation, xeromorphic scrub and ever green microphyll forest; wild life habitats, mainly in the floristic plateau, mangroves and lagoon systems in the southern border; in the structure, and uniqueness of the natural landscape, which becomes more critical with the proximity of areas of technical services (elevated tank, power plant, etc.); and the drainage and surface water runoff area [9].

- Cycle 3 Operation: an increased load of tourists and workers occurs, temporary facilities are located in the beach area, solid waste and higher consumption of fresh water and energy, among others are generated [7]. In the third cycle of operation, the impact will be caused by the disruption caused by the excessive number of people in the area and high degree of urbanization, an effect that begins at the planning and design stage. Another impact is the increase in noise, temperature and air pollution by paving and designs for hotels that do not promote the use of passive solar and bioclimatic design, as well as the power plant fuel oil. They produce more positive impact on social structures, through increased employment and the labor force of higher qualifications, than that of the construction cycle [9].

- Cycle 4 Closure or Abandonment: linked to the closure of the temporary facilities for the builder, degradation of landscapes and impact to the coastal zone and the beach as well as the closure of mines and quarries extracting building materials [7]. In the last cycle of closure, abandonment and recycling the landscape, fauna, geomorphology, and surface and ground water is affected. On a positive note, the possible restoration of an abandoned quarry on the edge of the tourist road, and the dismantling of some of the temporary facilities is appreciated [9].

\section{Case Study of Projects in Cayo Coco, Cuba}

Cayo Coco covers an area of $370 \mathrm{Km}^{2}$, the second largest island of the archipelago Sabana-Camaguey. The island is administered by the Morón municipality, located to the north of Ciego de Avila, Cuba.

The sampling site on the northern shore of the cay includes reefs, seagrass beds, and a permanently flooded red mangrove forest, and is named after the white ibis (Eudocimus albus) is a species of bird in the ibis family [3].

Historically, Cayo Coco has been virtually devoid of human population. The social and economic assimilation of Cayo Coco, and adjacent cays of the archipelago took place at the beginning of the 20th century, characterized mainly by forest exploitation and charcoal production [3].

There are three beaches with calm waters with an approximate length of $27 \mathrm{~km}$. Beaches are attractive for tourists and the massive coral reef off the north coast. The most spectacular beaches are: Las Coloradas, Playa Larga, El Paso, and Flamencos. 
The construction projects which are analyzed are located in the Flamenco Sector with the distances established within the legal framework known as the Decree-Law on Coastal Zones. The project is located in an area of 106 hectares and there is expected to be the planning for over 4250 tourist rooms; with a density of 40 inhabitants per hectare (in Hab./Ha) in Flamenco, which is excessive considering the high natural values and fragility of this area.

\section{Results and Discussion}

The methods for assessing the impact were applied to the case study in Flamenco Beaches, Cayo Coco; as was the identification matrix of impacting architecture actions that were assessed in the tourism projects taking into account the lifecycle analysis (Table 2).

The adverse environmental impact of building lifecycles on the impacted environmental factors (F) are grouped into the environment in accordance with the environmental components (Tables 3-6).

Architectural projects of tourism in cycle 1 are not sustainable in fragile ecosystems. Designers have not enough to design environmental culture. Investors also have high environmental awareness to request projects that are ecological in design.

The traditional construction methods in fragile island ecosystems have produced high levels of negative impacts on biodiversity, air, noise, geology during the cycle 2 of construction like liquid waste pollution and solid waste pollution; these impacts increase in the operation tourism cycle 3 with degradation of landscapes and dumpings and beach.

During the cycle of construction the contamination of lagoon fills with foreign material in several areas; as with the loss of quality of seawater and the beach through the dragging of sediment and dust, which added to the excessive load, and the very beach erosion, can degrade this valuable unit within a few years.

Table 2. Impacting actions of the projects (A) in Flamenco Beaches, Cayo Coco.

\begin{tabular}{|c|c|c|c|c|}
\hline A & Cycle 1 Projects & Cycle 2 Construction & Cycle 3 Operation & Cycle 4 Closure \\
\hline A1. Geological research & 1 & 0 & 0 & 0 \\
\hline A2. Urbanization overload & 1 & 0 & 0 & 0 \\
\hline A3. Recreational beach facilities & 0.84 & 0 & 0 & 0 \\
\hline A4. Overload of people & 0.84 & 0.97 & 0 & 0 \\
\hline A5. Air pollution & 0 & 1 & 0 & 0 \\
\hline A6. Liquid waste pollution & 0 & 1 & 0 & 0 \\
\hline A7. Solid waste pollution & 0 & 1 & 0 & 0 \\
\hline A8. Earthworks & 0 & 1 & 0 & 0 \\
\hline A9. Transportation of materials & 0 & 1 & 0 & 0 \\
\hline A10. Prefabricated assembly & 0 & 1 & 0 & 0 \\
\hline A11. Natural landscape construction & 0 & 1 & 0 & 0 \\
\hline A12. Exotic green area & 0 & 1 & 0 & 0 \\
\hline A13. Paving of roads & 0 & 0.79 & 0 & 0 \\
\hline A14. Dumping of waste & 0 & 1 & 1 & 0 \\
\hline A15. Excessive vehicle traffic & 0 & 0.84 & 0.72 & 0 \\
\hline A16. Beach facilities & 0 & 0 & 0.76 & 0 \\
\hline A17. Power plant & 0 & 0 & 1 & 0 \\
\hline A18. Temporary facilities & 0 & 0 & 0.78 & 0.84 \\
\hline A19. Degradation of landscapes & 0 & 0 & 1 & 1 \\
\hline A20. Dumping sand beach & 0 & 0 & 0.72 & 0.72 \\
\hline A21. Abandoned quarry & 0 & 0 & 0 & 1 \\
\hline
\end{tabular}


Table 3. Impact identification matrix (I) by Actions (A) in Cycle 1.

\begin{tabular}{lcccc}
\hline \multicolumn{1}{c}{ Environmental impact factor (F) } & A1 & A2 & A3 & A4 \\
\hline F1 Temperature & 0 & 1 & 0 & 0.82 \\
F2 Air & 1 & 1 & 0.84 & 0.84 \\
F3 Noise & 1 & 1 & 0.84 & 0.88 \\
F4 Geology & 1 & 1 & 0 & 0.84 \\
F5 Sandstones & 1 & 1 & 0 & 1 \\
F6 Rocks & 0 & 1 & 0.84 & 1 \\
F7 Lagoons & 0 & 1 & 1 & 0.84 \\
F8 Cumulative coastal plain & 1 & 0 & 0.84 & 0.84 \\
F9 Surface water & 0 & 1 & 0.84 & 0.92 \\
F10 Groundwater & 1 & 1 & 0.84 & 0.84 \\
F11 Surface drainage & 1 & 1 & 0.84 & 0.93 \\
F12 Landscape structure & 1 & 1 & 0.84 & 0.84 \\
F13 Coastal vegetation & 1 & 1 & 0.84 & 0.95 \\
F14 Xeromorphic Scrub & 1 & 1 & 0.84 & 0.84 \\
F15 Forest microphyll & 1 & 1 & 0 & 0.81 \\
F16 Endemic fauna & 1 & 1 & 0.84 & 0.81 \\
F17 Population dynamics & & 1 & 0.84 & 0.81 \\
F18 Temporary workforce & 1 & 1 & 0.84 & \\
F19 Urban infrastructure & & & \\
\hline
\end{tabular}

Table 4. Impact identification matrix (I) by Actions (A) in Cycle 2.

\begin{tabular}{ccccccccccccc}
\hline F & A4 & A5 & A6 & A7 & A8 & A9 & A10 & A11 & A12 & A13 & A14 & A15 \\
\hline F1 & 0.97 & 1 & 0 & 0 & 1 & 1 & 0 & 1 & 0 & 0.79 & 1 & 0.84 \\
F2 & 0.97 & 1 & 1 & 1 & 1 & 1 & 1 & 1 & 0 & 0.79 & 1 & 0.84 \\
F3 & 0.97 & 1 & 0 & 0 & 1 & 1 & 1 & 1 & 0 & 0.79 & 1 & 0.84 \\
F4 & 0 & 0 & 0 & 0 & 1 & 0 & 1 & 1 & 0 & 0.79 & 0 & 0 \\
F5 & 0.97 & 1 & 0 & 1 & 1 & 0 & 1 & 1 & 0 & 0.79 & 0 & 0 \\
F6 & 0 & 0 & 0 & 1 & 1 & 0 & 1 & 0 & 0 & 0.79 & 1 & 0 \\
F7 & 1 & 1 & 1 & 1 & 1 & 1 & 1 & 1 & 1 & 1 & 1 & 1 \\
F8 & 0.97 & 0 & 1 & 0 & 1 & 0 & 1 & 1 & 0 & 0.79 & 0 & 0 \\
F9 & 0.97 & 0 & 1 & 1 & 1 & 0 & 1 & 0 & 1 & 0.79 & 1 & 0 \\
F10 & 0.97 & 0 & 1 & 1 & 1 & 0 & 1 & 0 & 1 & 0.79 & 1 & 0 \\
F11 & 0.97 & 0 & 1 & 1 & 1 & 0 & 1 & 1 & 1 & 0.79 & 1 & 0.84 \\
F12 & 0.97 & 0 & 1 & 1 & 1 & 1 & 0 & 1 & 1 & 0.79 & 1 & 0.84 \\
F13 & 0.97 & 1 & 1 & 1 & 1 & 0 & 1 & 1 & 1 & 0.79 & 0 & 0.84 \\
F14 & 0.97 & 1 & 1 & 1 & 1 & 0 & 1 & 1 & 1 & 0.79 & 0 & 0.84 \\
F15 & 0.97 & 1 & 1 & 1 & 1 & 0 & 1 & 1 & 1 & 0.78 & 0 & 0.83 \\
F16 & 0.97 & 1 & 1 & 1 & 1 & 0 & 1 & 1 & 1 & 0.78 & 1 & 0.83 \\
F17 & 0.97 & 1 & 0 & 0 & 0 & 1 & 0 & 0 & 0 & 0.77 & 0 & 0.82 \\
F18 & 0 & 1 & 1 & 1 & 1 & 1 & 0 & 0 & 1 & & 1 & 0.81 \\
F19 & 0 & & 1 & 1 & 1 & 1 & 1 & 0 & 1 & & 1 & 0.81 \\
\hline & & & & & & & & & & & 0.879 \\
\end{tabular}


Table 5. Impact identification matrix (I) by Actions (A) in Cycle 3.

\begin{tabular}{|c|c|c|c|c|c|c|c|}
\hline $\mathrm{F}$ & A14 & A15 & A16 & A17 & A18 & A19 & A20 \\
\hline $\mathrm{F} 1$ & 0 & 0.72 & 0 & 1 & 0 & 0 & 0 \\
\hline F2 & 1 & 0.72 & 0.76 & 1 & 0.78 & 1 & 0.72 \\
\hline F3 & 1 & 0.72 & 0.76 & 1 & 0.78 & 0 & 0.72 \\
\hline $\mathrm{F} 4$ & 0 & 0 & 0 & 0 & 0.78 & 1 & 0.72 \\
\hline F5 & 0 & 0 & 0.76 & 0 & 0 & 1 & 0.72 \\
\hline F6 & 1 & 0 & 0 & 0 & 0.78 & 0 & 0.72 \\
\hline F7 & 1 & 1 & 1 & 1 & 0.78 & 1 & 1 \\
\hline F8 & 1 & 1 & 1 & 1 & 1 & 1 & 1 \\
\hline F9 & 1 & 0.72 & 0 & 1 & 0.78 & 1 & 0.72 \\
\hline F10 & 1 & 0 & 0 & 1 & 0.78 & 0 & 0 \\
\hline F11 & 1 & 0.72 & 0.76 & 1 & 0.78 & 1 & 0.72 \\
\hline F12 & 1 & 0.72 & 0.76 & 1 & 0.78 & 1 & 0.72 \\
\hline F13 & 0 & 0.72 & 0.76 & 1 & 0 & 1 & 0.72 \\
\hline F14 & 0 & 0.72 & 0 & 1 & 0.78 & 1 & 0 \\
\hline F15 & 0 & 0.72 & 0 & 1 & 0.78 & 1 & 0 \\
\hline F16 & 1 & 0 & 0.76 & 1 & 0.78 & 1 & 0.72 \\
\hline F17 & 0 & 0.72 & 0.76 & 1 & 0.78 & 0 & 0.72 \\
\hline F18 & 1 & 0.72 & 0 & 1 & 0.78 & 0 & 0.72 \\
\hline F19 & 1 & 0.72 & 0.76 & 1 & 0.78 & 1 & 0.72 \\
\hline
\end{tabular}

Table 6. Impact identification matrix (I) by Actions (A) in Cycle 4.

\begin{tabular}{|c|c|c|c|c|}
\hline $\mathrm{F}$ & A18 & A19 & A20 & A21 \\
\hline F1 & 0 & 0 & 0 & 0 \\
\hline F2 & 0 & 0 & 0.71 & 1 \\
\hline F3 & 0.83 & 1 & 0.72 & 1 \\
\hline $\mathrm{F} 4$ & 0 & 0 & 0.71 & 1 \\
\hline F5 & 0 & 0 & 0.71 & 1 \\
\hline F6 & 0 & 1 & 0.72 & 1 \\
\hline F7 & 1 & 1 & 1 & 1 \\
\hline F8 & 1 & 1 & 1 & 1 \\
\hline F9 & 0.84 & 1 & 0.71 & 1 \\
\hline F10 & 0 & 0 & 0.72 & 1 \\
\hline F11 & 0 & 0 & 0.72 & 1 \\
\hline F12 & 0.83 & 1 & 0.71 & 1 \\
\hline F13 & 0 & 0 & 0.72 & 0 \\
\hline F14 & 0 & 0 & 0 & 0 \\
\hline F15 & 0 & 0 & 0 & 0 \\
\hline F16 & 0 & 0 & 0.71 & 1 \\
\hline F17 & 0.82 & 1 & 0.7 & 0 \\
\hline F18 & 0.82 & 1 & 0.7 & 1 \\
\hline F19 & 0.82 & 1 & 0.7 & 0 \\
\hline
\end{tabular}




\section{Conclusion}

The level of trainings and hands-on experiences of personnel from relevant institution and environmental agencies is generally high. Supported with appropriate technical assistance, the designers and architects can undertake research and monitoring programs, integrated coastal management, and environmental planning and design, undoubtedly at the level of international ecological standards. However, national construction experts will need targeted support in environmental specialized areas, as well as in others areas where there is a need to keep abreast with recent sustainable development.

\section{References}

[1] Roberts, S. and Lewis-Cameron, A. (2010) Small Island Developing Status: Signs and Prospects. In: Lewis-Cameron, A., Ed., Marketing Island Destinations: Concepts and Cases, Elsevier, Oxford, 1-10. http://dx.doi.org/10.1016/B978-0-12-384909-0.00001-5

[2] Amoamo, M. (2011) The Mitigation of Vulnerability: Mutiny, Resilience and Reconstitution. A Case Study of Pitcairn Island. The International Journal of Research into Island Cultures, 5, 69-93.

[3] Alcolado, P.M., García, E.E. and Arellano-Acosta, M. (2011) Ecosistema Sabana-Camagüey: Estado, avances y desafíos en la protección y uso sostenible de la biodiversidad. Editorial Academia, Habana, 76.

[4] García, D., et al. (2014) Propuesta de metodología de gestión ambiental para agro ecosistemas con riesgos a la salud por contaminación química. Revista Habanera de Ciencias Médicas, 13. http://scielo.sld.cu/scielo.php?pid=S1729-519X2014000400011\&script=sci_arttext\&tlng=en

[5] Gutiérrez, L. (2015) Impact Assessment of Tourism Construction in Cuba. Journal of Building Construction and Planning Research, 3, 10-17. http://dx.doi.org/10.4236/jbcpr.2015.31002

[6] O’Reilly, V., Bancrofft, R. and Ruiz, L. (2010) Las tecnologías del concreto en su ciclo de vida. México. Concreto y Cemento: Investigación y Desarrollo. Revista CONPAT, 1, 42-47.

[7] Cárdenas, J.P., Muñoz, E., Riquelme, C. and Hidalgo, F. (2015) Análisis de ciclo de vida simplificado aplicado a viviendas de paneles SIP (structural insulated panels). Revista Ingeniería de Construcción, 30. http://www.ricuc.cl/index.php/ric/article/view/555/pdf

[8] Zabalza Bribián, I., Aranda Usón, A. and Scarpellini, S. (2009) Life Cycle Assessment in Buildings: State-of-the-Art and Simplified LCA Methodology as a Complement for Building Certification. Building and Environment, 44, 25102520. http://dx.doi.org/10.1016/j.buildenv.2009.05.001

[9] Gutiérrez, L. (2015) The Environmental Effects of Tourism Architecture on Island Ecosystem in Cayo Guillermo, Cuba. Journal of Environmental Protection, 6, 1057-1065. http://dx.doi.org/10.4236/jep.2015.69093 